\title{
Metallization of Various Polymers by Cold Spray
}

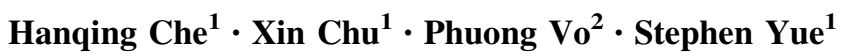

Submitted: 29 July 2017 / in revised form: 20 October 2017/Published online: 14 November 2017

(C) ASM International 2017

\begin{abstract}
Previous results have shown that metallic coatings can be successfully cold sprayed onto polymeric substrates. This paper studies the cold sprayability of various metal powders on different polymeric substrates. Five different substrates were used, including carbon fiber reinforced polymer (CFRP), acrylonitrile butadiene styrene (ABS), polyether ether ketone (PEEK), polyethylenimine (PEI); mild steel was also used as a benchmark substrate. The CFRP used in this work has a thermosetting matrix, and the ABS, PEEK and PEI are all thermoplastic polymers, with different glass transition temperatures as well as a number of distinct mechanical properties. Three metal powders, tin, copper and iron, were cold sprayed with both a low-pressure system and a high-pressure system at various conditions. In general, cold spray on the thermoplastic polymers rendered more positive results than the thermosetting polymers, due to the local thermal softening mechanism in the thermoplastics. Thick copper coatings were successfully deposited on PEEK and PEI. Based on the results, a method is proposed to determine the feasibility and deposition window of cold spraying specific metal powder/polymeric substrate combinations.
\end{abstract}

This article is an invited paper selected from presentations at the 2017 International Thermal Spray Conference, held June 7-9, 2017, in Düsseldorf, Germany, that has been expanded from the original presentation.

Hanqing Che

hanqing.che@mail.mcgill.ca

1 Department of Mining and Materials Engineering, McGill University, Montreal H3A 0C5, Canada

2 National Research Council Canada, Boucherville J4B 6Y4, Canada
Keywords cold spray $\cdot$ deposition window $\cdot$ metallization of polymers $\cdot$ polymeric substrate

\section{Introduction}

Polymers and polymer matrix composites are increasingly used, but their low electrical conductivity has limited their application. Previous results at McGill University show that cold spray of metal powders onto the carbon fiber reinforced polymer (CFRP) substrates is viable (Ref 1,2). This paper presents the effect of polymeric substrates on the cold sprayability of various metal powders. Five different substrates were used in this work, including CFRP, ABS (acrylonitrile butadiene styrene), PEEK (polyether ether ketone), PEI (polyethylenimine); mild steel was also used as a benchmark substrate. It has been reported by researchers that thermoplastics and thermosets render different responses during cold spray of metallic powders (Ref $3,4)$. The CFRP used in this work has a thermosetting matrix, and the ABS, PEEK and PEI are all thermoplastic polymers, with different glass transition temperatures as well as a number of distinct mechanical properties. The glass transition temperature, $\mathrm{T}_{\mathrm{g}}$, is a temperature region over which the reversible transition between a brittle, glasslike state $\left(\mathrm{T}<\mathrm{T}_{\mathrm{g}}\right)$ and a rubber-like state $\left(\mathrm{T}>\mathrm{T}_{\mathrm{g}}\right)$ occurs in an amorphous polymer or in amorphous regions of a partially crystalline polymer (Ref 5).

PEEK and PEI are both high-performance polymers that have been widely used in a wide range of applications, especially those that involve high-temperature exposure. PEEK is a semicrystalline thermoplastic that offers excellent mechanical properties, chemical and wear resistance, high continuous-use temperature $\left(300{ }^{\circ} \mathrm{C}\right.$ for short-time and $250{ }^{\circ} \mathrm{C}$ for long-time exposure), low smoke/toxic gas 
emission, etc. (Ref 6, 7). PEI, on the other hand, is an amorphous polymer with good mechanical properties. It is a cheaper alternative to PEEK despite offering a lower continuous performance temperature of $170{ }^{\circ} \mathrm{C}$ (Ref 6). ABS is a common engineering plastic, which normally cannot be used at elevated temperatures [usually below $70{ }^{\circ} \mathrm{C}$ (Ref 6)]. It has excellent impact resistance, stiffness and toughness, and its main advantage is its low cost (Ref 8).

Three single-component powders, tin, copper and iron, were used in this work. Copper and tin were used in the previous CFRP experiments (Ref 1); iron was chosen because it has a relatively higher critical velocity. The critical velocity, $v_{\text {crit }}$, is an impact velocity limit above which deposition starts and further increases to a saturation limit up to $100 \%$ (Ref 9). The $v_{\text {crit }}$ value of iron is calculated to be higher than $600 \mathrm{~m} / \mathrm{s}$ without heating (Ref 10), higher than those of copper (460$500 \mathrm{~m} / \mathrm{s}$ ) and tin (below $200 \mathrm{~m} / \mathrm{s}$ ) (Ref 10), and this enables an investigation over a range of $v_{\text {crit }}$. Cold spray experiments were performed with both a low-pressure CenterLine system and a high-pressure Plasma Giken system at various conditions.

\section{Experimental Methods}

\section{Starting Materials}

Three single-component powders, copper, tin and iron, were used in this work. The average particle size was measured with a laser scattering particle size analyzer (LA920; HORIBA, Japan), and the results are listed in Table 1. Also listed in Table 1 are the Vickers hardness measurements of the three powders. The scanning electron microscope images and cross-sectional optical micrographs of the feedstock powders are shown in Fig. 1. It can be seen that the iron powder has a mixed morphology (i.e., a combination of spherical and irregular) and the particles are larger than the other two powders.

The substrates used in this work were CFRP (supplied by Bombardier Aerospace, Montreal, Canada), commercially available ABS, PEEK, PEI and 1020 mild steel. Some common properties of the three thermoplastic materials are listed in Table 2. For the cold spray experiments, sheet sections of dimensions
$7 \times 5 \mathrm{~cm}$ were used as the substrates. Prior to the cold spray experiments, the CFRP sections were degreased with acetone, the ABS, PEEK and PEI sections were degreased with ethyl alcohol, and the mild steel sections were degreased with acetone and grit-blasted with 24 grit alumina.

\section{Cold Spray and Diagnostics}

Cold spray experiments were carried out at the McGillNRC cold spray facility at National Research Council Canada, Boucherville. Both a low-pressure system (SST, CenterLine, Canada) and a high-pressure system (PSC-800, Plasma Giken, Japan) were used to investigate the cold sprayability of the metal powders onto polymeric substrates at a wide range of particle velocities. It should be noted that there are a number of differences between the two different systems (e.g., geometry of the nozzle, powder injection mode and location of the thermocouple). The two systems were used to achieve a wide range of particle velocities, and no direct comparison was made between the two cold spray systems. Nitrogen was selected as the carrier gas for both systems, and the above-mentioned three powders were sprayed at various conditions, which are shown in detail in Table 3. Tin was cold sprayed at $200{ }^{\circ} \mathrm{C}$ to avoid melting, copper was cold sprayed at $425^{\circ} \mathrm{C}$, and iron was cold sprayed at both 200 and $425^{\circ} \mathrm{C}$. Other process parameters for the CenterLine system were basically those that resulted in successful deposition in our previous work (Ref 1). For the Plasma Giken system, the $25 \mathrm{~mm} \mathrm{~s}^{-1}$ gun travel speed is relatively low for this system, but was kept the same as in the CenterLine system for direct comparison purpose. The powder feeder was set at 1 RPM, and the actual feeding rate was measured for each powder before the cold spray.

The particle velocity measurements at different conditions were measured by using a Coldspraymeter time-offlight particle diagnostic system (DPV2000, Tecnar Automation, Canada), which uses a laser diode $(7 \mathrm{~W}$, $\lambda=830 \mathrm{~nm}$ ) to illuminate the in-flight particles (Ref 11). The standoff distance was kept the same as those listed in Table 3, and the laser was focused on the "center" of the stream, where most particles were detected. For each measurement, a total number of 300 particles were detected.
Table 1 Feedstock powders used in this work

\begin{tabular}{lllcc}
\hline Powder & \multicolumn{1}{c}{ Morphology } & \multicolumn{1}{c}{ Supplier } & $\mathrm{D}_{\text {avg }}, \mu \mathrm{m}$ & Hardness, HV \\
\hline $\mathrm{Cu}$ & Relatively spherical & Plasma Giken, Japan & 29 & 55 \\
$\mathrm{Sn}$ & Relatively spherical & CenterLine SST, Canada & 17 & 11 \\
$\mathrm{Fe}$ & Mixed & Quebec Metal Powders, Canada & 35 & 129 \\
\hline
\end{tabular}



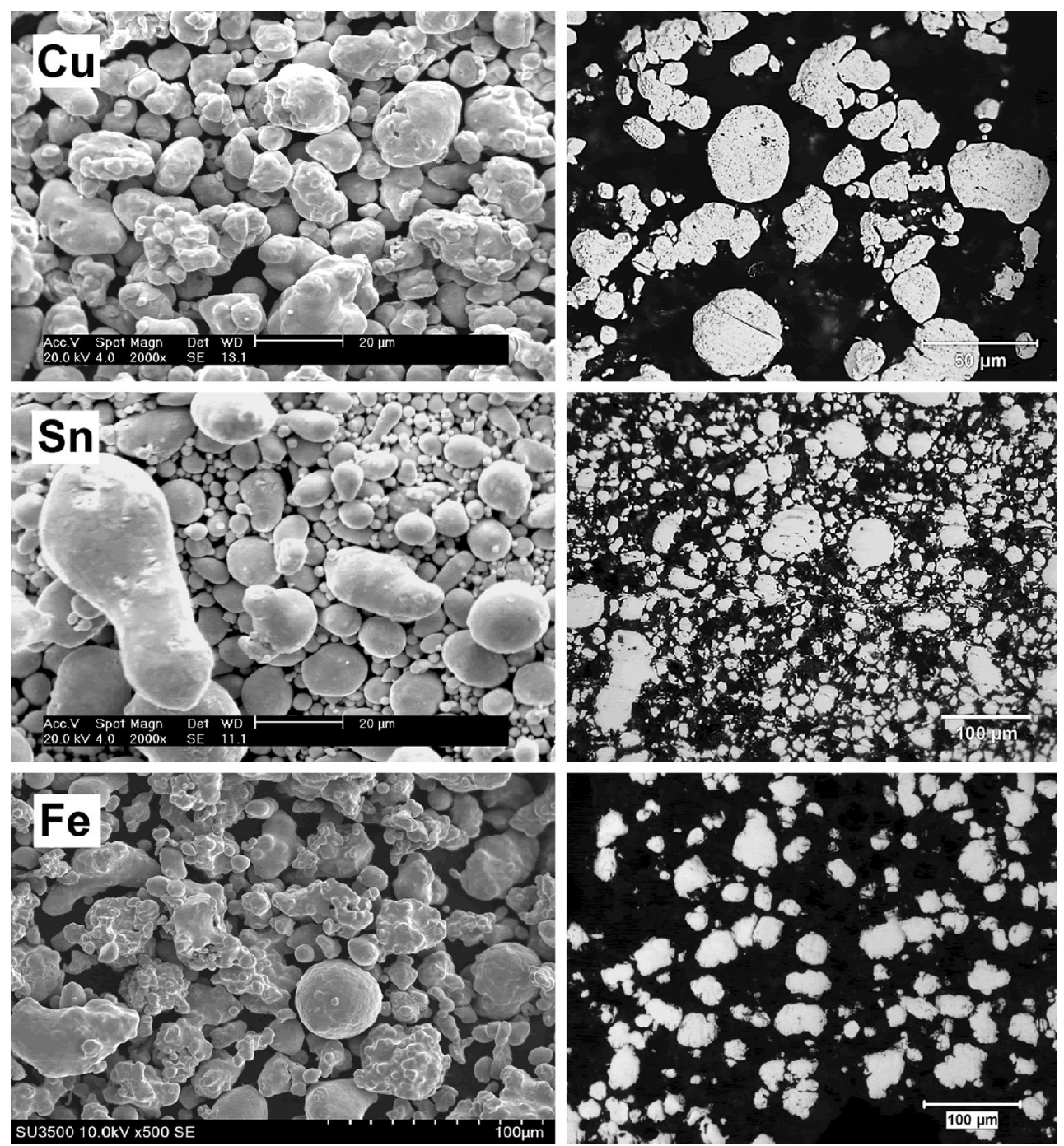

Fig. 1 SEM images (left) and cross-sectional optical micrographs (right) of the feedstock powders (images are at different magnifications)

Table 2 Some properties of the three thermoplastic materials used in this work, data summarized from (Ref 18)

\begin{tabular}{llll}
\hline Property & ABS & PEEK & \multicolumn{1}{c}{ PEI } \\
\hline $\mathrm{T}_{\mathrm{g}},{ }^{\circ} \mathrm{C}$ & 105 & 145 & 215 \\
Hardness, M & $30-50$ & $55-100$ & $109-112$ \\
Tensile strength, MPa & $30-60$ & $70-100$ & $90-100$ \\
ASTM D256 Impact, J/m & $100-350$ & $80-85$ & $50-60$ \\
\hline
\end{tabular}

Deposition efficiency (DE), which is the weight change of the substrate divided by the overall weight of powder sprayed out during the time that the gun is actually over the sample, was measured at various conditions.

After the cold spray experiments, the coated samples were cut, prepared as metallographic specimens and characterized with a Nikon Epiphot 200 optical microscope.

\section{Results}

\section{Velocity Measurements}

The measured mean particle velocity, $v_{50}$, for tin sprayed at $200{ }^{\circ} \mathrm{C}$ with the low-pressure system and copper sprayed at $425{ }^{\circ} \mathrm{C}$ with both the low-pressure and the high-pressure systems at various gas pressures is shown in Fig. 2(a). For copper sprayed at gas pressures below 1.0 MPa (150 psi), the particle velocities were too low to be measured by the current setup. It can be seen that for copper and tin sprayed with a specific system, $v_{50}$ increased basically with the gas pressure. This agrees with the expectation that high gas pressures lead to high particle velocities (Ref 12). The particle velocities of copper showed two distinct trends at low pressures and high pressures with different slopes, and such a difference results from the differences between the two cold spray systems (e.g., nozzle geometry and powder 
Table 3 Process parameters for cold spray

\begin{tabular}{|c|c|c|c|c|c|}
\hline Powder & Temperature, ${ }^{\circ} \mathrm{C}$ & Pressure, MPa (psi) & Standoff distance, $\mathrm{mm}$ & Gun travel speed, $\mathrm{mm} \mathrm{s}^{-1}$ & Feeding, $\mathrm{g} \mathrm{min}^{-1}$ \\
\hline \multicolumn{6}{|c|}{ Low-pressure CenterLine system } \\
\hline \multirow[t]{2}{*}{$\mathrm{Sn}$} & 200 & $(75-200)$ & 18 & 25 & 10 \\
\hline & & $0.5-1.4$ & & & \\
\hline \multirow[t]{2}{*}{$\mathrm{Fe}$} & 200 & $(75-200)$ & 18 & 25 & 16 \\
\hline & & $0.5-1.4$ & & & \\
\hline \multirow[t]{2}{*}{$\mathrm{Fe}$} & 425 & $(50-200)$ & 18 & 25 & 16 \\
\hline & & $0.3-1.4$ & & & \\
\hline \multirow[t]{2}{*}{$\mathrm{Cu}$} & 425 & $(50-200)$ & 18 & 25 & 11 \\
\hline & & $0.3-1.4$ & & & \\
\hline \multicolumn{6}{|c|}{ High-pressure Plasma Giken system } \\
\hline $\mathrm{Fe}$ & 200 & $2-4$ & 40 & 25 & 16 \\
\hline $\mathrm{Fe}$ & 425 & $2-4.9$ & 40 & 25 & 17 \\
\hline $\mathrm{Cu}$ & 425 & $2-4.9$ & 40 & 25 & 19 \\
\hline
\end{tabular}
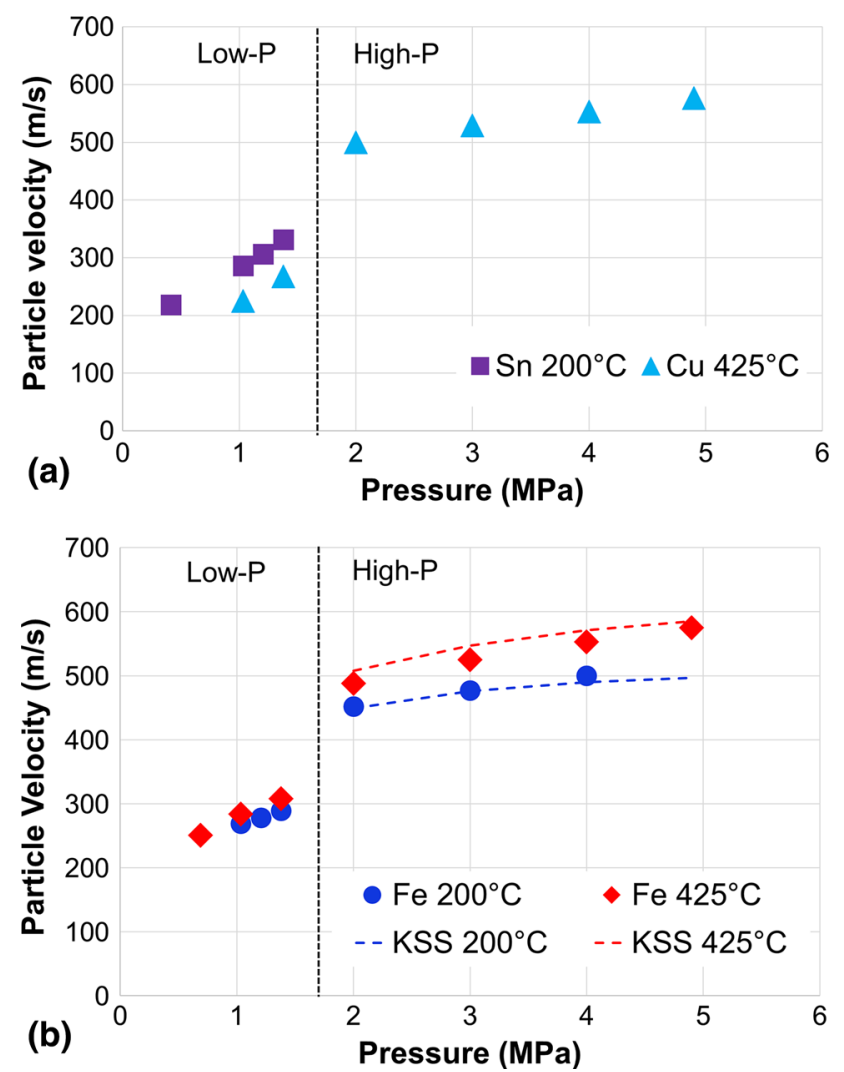

Fig. 2 The measured mean particle velocities as a function of gas pressure for (a) Sn sprayed at $200{ }^{\circ} \mathrm{C}$ and $\mathrm{Cu}$ sprayed at $425^{\circ} \mathrm{C}$, and (b) $\mathrm{Fe}$ sprayed at $200{ }^{\circ} \mathrm{C}$ and $425^{\circ} \mathrm{C}$, with both the low-pressure (to the left of the dashed line) and high-pressure (to the right of the dashed line) cold spray systems

feeder type). It can also be seen that the velocities of copper were lower than those of tin cold sprayed at the same conditions, due to the larger particle size and higher density of the copper powder.
For iron powder, the measured $v_{50}$ at 200 and $425^{\circ} \mathrm{C}$ with both cold spray systems as a function of gas pressure is shown in Fig. 2(b). Similarly, $v_{50}$ generally increased with gas pressure and the results at both temperatures showed two distinct trends in the low-pressure and highpressure area. In addition, the particle velocities were not strongly influenced by temperature at low pressure, and with the high-pressure system, there was only a slight effect of the difference in temperature, with $425{ }^{\circ} \mathrm{C}$ giving a slightly higher velocity than $200{ }^{\circ} \mathrm{C}$. At high pressures, a comparison was made between the experimental results in this work and the calculated results using the commercially available (CKinetic Spray Solutions (KSS) software (Kinetic Spray Solutions, Germany), for which the results are shown by the dashed lines. The software's fluid mechanics module (Ref 13, 14) enables the calculation of gas and particle velocities for a given nozzle (shape, geometry, etc.), with the input of process parameters and particle size (same value as in the experiments). The experimental results are within $5 \%$ of the simulated results. In addition, the velocities of copper and iron sprayed at $425{ }^{\circ} \mathrm{C}$ were similar at all conditions.

\section{Deposition Efficiency and Microstructure}

\section{Tin}

The measured DEs of tin cold sprayed at $200{ }^{\circ} \mathrm{C}$ on five substrates at various gas pressures are present in Fig. 3. The DE results on the steel substrate can be considered as benchmarks. At $0.5 \mathrm{MPa}$ (75 psi), no deposition was achieved on steel, even though the mean particle velocity, $v_{50}$, reached $230 \mathrm{~m} / \mathrm{s}$, which is above $v_{\text {crit }}$, for tin, predicted by others to be $160-180 \mathrm{~m} / \mathrm{s}$ (Ref 13). At a higher gas pressure of $1.0 \mathrm{MPa}(150 \mathrm{psi})$, when $v_{50}$ reached $286 \mathrm{~m} / \mathrm{s}$, 
deposition started on steel. The DE on steel increased significantly at gas pressure of $1.2 \mathrm{MPa}(175 \mathrm{psi}$, $v_{50}=306 \mathrm{~m} / \mathrm{s}$ ) but did not show further improvement at 1.4 $\mathrm{MPa}\left(200 \mathrm{psi}, v_{50}=331 \mathrm{~m} / \mathrm{s}\right)$.

For ABS, the deposition behavior was similar to that on steel substrates, deposition started at $1.0 \mathrm{MPa}$ and increased at 1.2 and 1.4 MPa. However, DE on ABS at each condition was lower than that on steel at corresponding conditions. On CFRP and PEEK substrates, similar DE results were obtained, although one is thermoplastic and the other is a composite with a thermosetting matrix. For CFRP, there was slight erosion of the substrate at 0.5 and $1.0 \mathrm{MPa}$ since the measured DE values were slightly negative, whereas no weight change was found on PEEK substrates at these two conditions. At gas pressures of 1.2 and 1.4 MPa, deposition was achieved on CFRP and PEEK, but the DE values for both substrates were much smaller than those on steel. No deposition was achieved on PEI at most conditions, with a maximum DE of $1 \%$ at 1.2 $\mathrm{MPa}$.

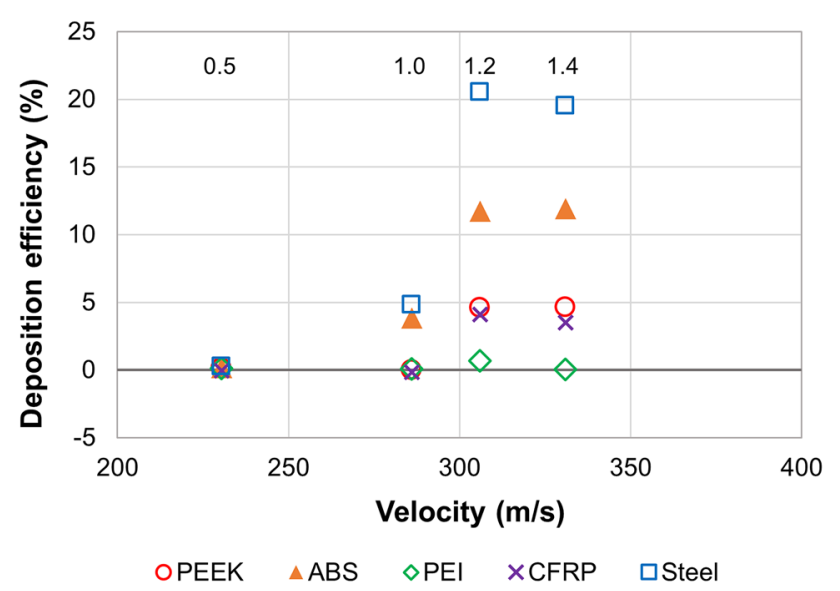

Fig. 3 DE of Sn cold sprayed at $200{ }^{\circ} \mathrm{C}$ onto various substrates as a function of mean particle velocity (numbers in the chart are pressures in $\mathrm{MPa}$ )
The cross-sectional microstructures of the tin coatings cold sprayed at $200{ }^{\circ} \mathrm{C}$ and $1.4 \mathrm{MPa}$ on ABS and PEEK, which showed the best deposition behavior, are present in Fig. 4. It can be seen that continuous tin coatings were deposited on both thermoplastics, but the coating on ABS is non-uniform and wavy, signifying local material removal (erosion) took place.

\section{Iron}

At $200{ }^{\circ} \mathrm{C}$, for all substrates at all gas pressures performed, no effective deposition can be achieved, with the maximum DE being lower than 1\% (not shown). This indicates that the particle velocities were below $v_{\text {crit }}$ at most conditions at $200{ }^{\circ} \mathrm{C}$ (maximum velocity at $4 \mathrm{MPa}, v_{50}=500 \mathrm{~m} / \mathrm{s}$ ). Among the polymeric substrates, the CFRP with a thermosetting matrix showed significant erosion with increasing gas pressure.

For iron cold sprayed at $425^{\circ} \mathrm{C}$, the measured $\mathrm{DE}$ results are present in Fig. 5. It can be seen that on steel substrates, deposition did not begin until $2.0 \mathrm{MPa}$, at pressures above which DE increased with increasing gas pressure. This suggests that the $v_{50}$ at $2.0 \mathrm{MPa}, 488 \mathrm{~m} / \mathrm{s}$, is near/just above the $v_{\text {crit }}$ for iron at this temperature. However, the magnitudes of DE for iron on steel were relatively low, even at $4.9 \mathrm{MPa}\left(v_{50}=575 \mathrm{~m} / \mathrm{s}\right)$, DE was only $25 \%$.

Two polymeric substrates, the CFRP and ABS, showed negative DE values, which signify substrate erosion. For CFRP, no deposition can be achieved and DE was negative for all gas pressures. At a gas pressure of $3 \mathrm{MPa}$ or higher, full-thickness removal/erosion of the CFRP substrate occurred, causing fracture of the substrates. ABS, the thermoplastic with the lowest $\mathrm{T}_{\mathrm{g}}$ and operating limit, showed low DE $(<2 \%)$ at low pressures $(1.4 \mathrm{MPa}$ and lower) and negative DE (2 and $3 \mathrm{MPa}$ ) and full-thickness erosion (4 and 4.9 $\mathrm{MPa}$ ) at high pressures. Some deposition, probably particle embedding, was achieved on ABS at pressures (0.3-1.4 $\mathrm{MPa}$ ) lower than the onset deposition pressure on steel $(2.0 \mathrm{MPa})$.
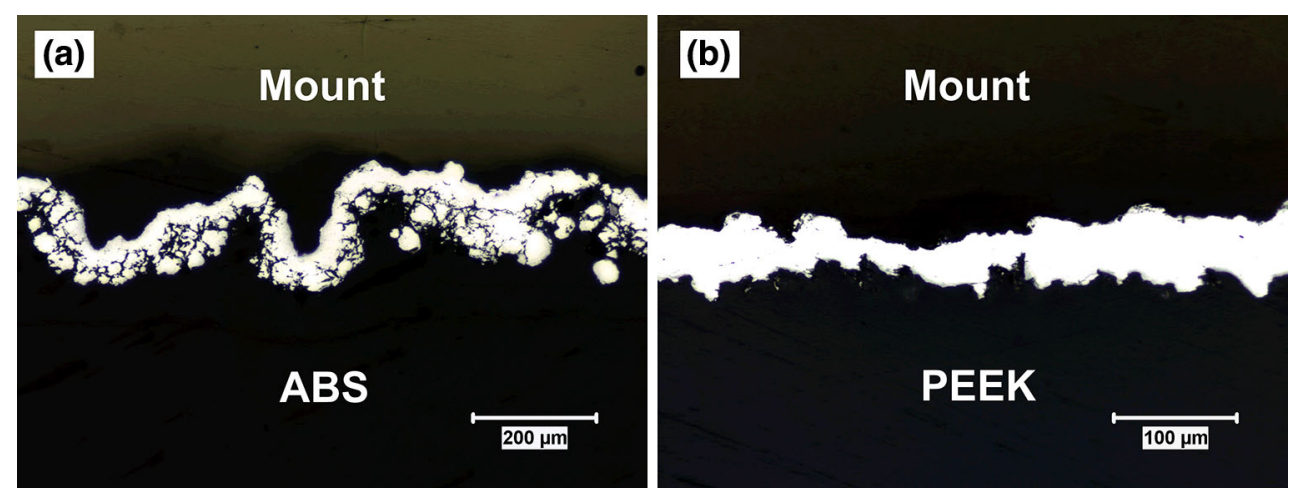

Fig. 4 Optical micrographs showing the cross sections of the Sn coatings cold sprayed at $200{ }^{\circ} \mathrm{C}$ and 1.4 MPa on (a) ABS and (b) PEEK 
No significant deposition was achieved on either PEEK or PEI, with a maximum DE below 3 and $2 \%$, respectively. DE on PEEK first increased slightly and then decreased with increasing particle velocity/gas pressure, and the same trend was observed on PEI substrates, for which DE became slightly negative at $4.9 \mathrm{MPa}$.

It should be noted that at low pressures (below 2.0 MPa), some deposition of iron was achieved on the thermoplastics, but not achieved on steel, and this indicates that the deposition was through particle embedding that is exclusive to the thermoplastics. The particle embedment can also be seen from the cross-sectional micrographs in Fig. 6.

\section{Copper}

The DE results for copper cold sprayed at $425^{\circ} \mathrm{C}$ are present in Fig. 7. It can be seen that the deposition of copper on the steel substrate started at a gas pressure of 1.0 MPa, corresponding to a $v_{50}$ of $225 \mathrm{~m} / \mathrm{s}$ in Fig. 2(a); then, DE increased with increasing gas pressure/particle

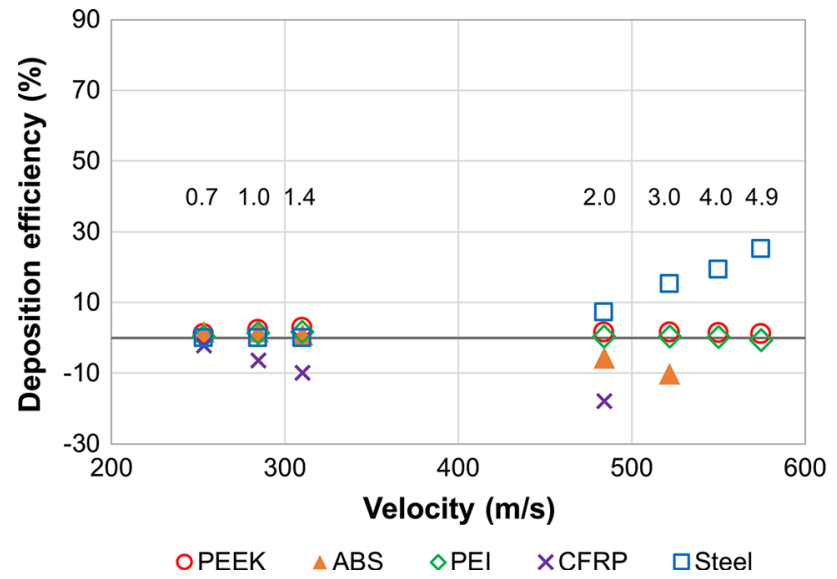

Fig. $5 \mathrm{DE}$ of Fe cold sprayed at $425{ }^{\circ} \mathrm{C}$ onto various substrates as a function of mean particle velocity (numbers in the chart are pressures in $\mathrm{MPa}$ ) velocity. At gas pressures higher than 2.0 MPa, DE was not successfully measured since the deposited coating kept falling off the substrate during cold spray, indicating lowstrength bonding with the substrate, probably caused by effects due to increasing coating thickness (e.g., thermal stress caused by coating contracting and/or bending during cooling). For CFRP, significant erosion was again observed, although the magnitudes of material loss were lower than those with the iron powder. ABS also showed deposition behavior similar to that in Fig. 5, low DEs $(<5 \%)$ at low pressures (1.4 MPa and lower) and erosion at high pressures (2 $\mathrm{MPa}$ and higher).

For PEEK and PEI, both materials showed an increasing trend of DE with increasing gas pressure/particle velocity. They exhibited low DEs $(<5 \%)$ at low pressures up to 1.4 MPa, although DE of copper on steel started to increase significantly at a lower gas pressure, 1.0 MPa. The highpressure system delivered an increase in DE on PEEK. This was comparable to DE on the steel substrate at $2.0 \mathrm{MPa}$, with increased DE at higher pressures/velocities. As for the PEI substrate, DE also increased largely starting from

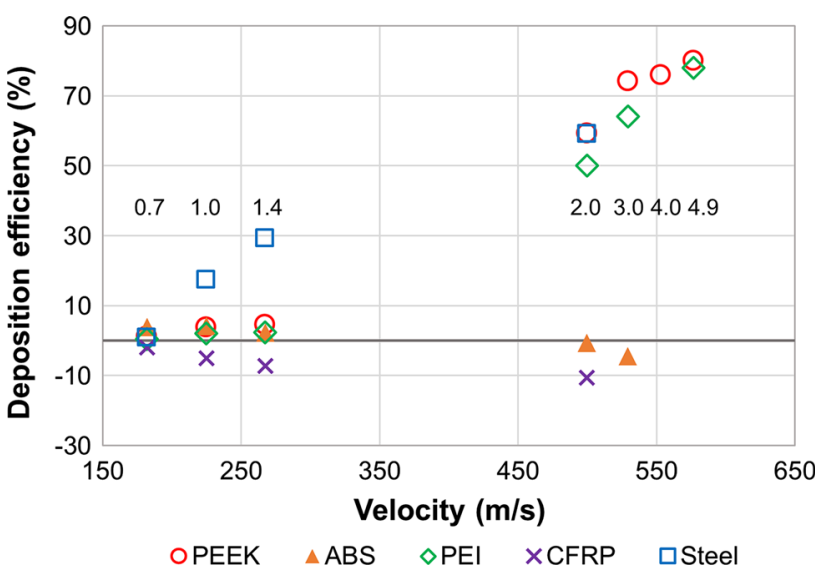

Fig. $7 \mathrm{DE}$ of $\mathrm{Cu}$ cold sprayed at $425^{\circ} \mathrm{C}$ onto various substrates as a function of mean particle velocity (velocity at $0.7 \mathrm{MPa}$ is an estimate, numbers in the chart are pressures in $\mathrm{MPa}$ )
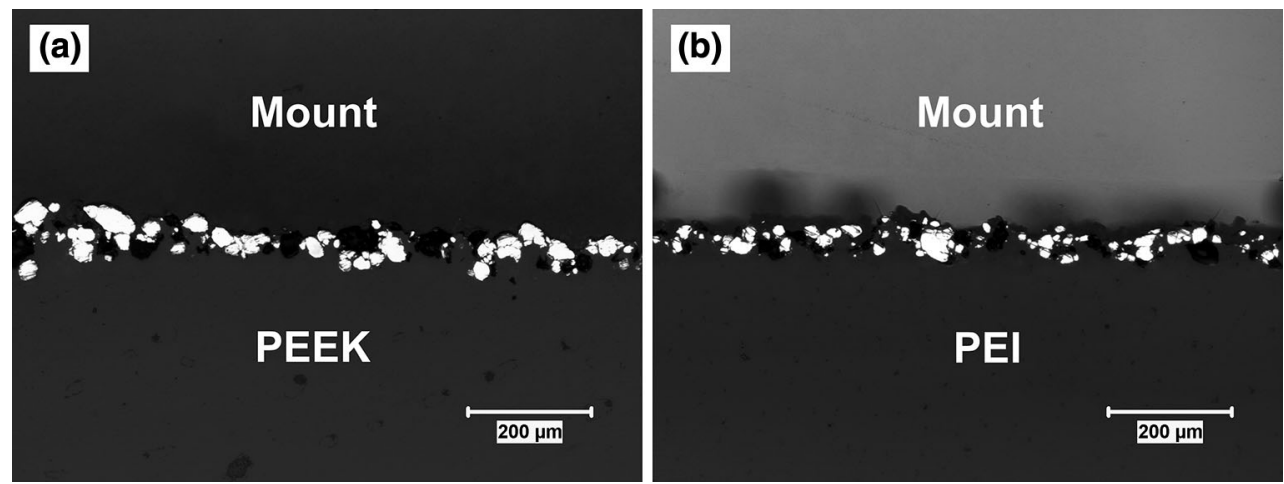

Fig. 6 Optical micrographs showing the cross sections of (a) PEEK and (b) PEI after cold spray of Fe at $425{ }^{\circ} \mathrm{C}$ and $1.4 \mathrm{MPa}$ 
2.0 MPa, but DE on PEI was lower than those on steel and PEEK substrates under the same conditions. The DE result on PEI at $4 \mathrm{MPa}$ was not successfully recorded due to the detachment of the coating during the process.

Figure 8 shows the cross-sectional optical micrographs of ABS and PEEK after cold spray of copper at $425^{\circ} \mathrm{C}$ at 1.0 and $2.0 \mathrm{MPa}$. At 1.0 $\mathrm{MPa}$, the pressure at which the deposition began on steel, considerable copper particle embedding was achieved on both ABS (Fig. 8a) and PEEK (Fig. 8c), but no continuous coating was formed. When the gas pressure was further increased to $2.0 \mathrm{MPa}$ with a Plasma Giken system, it can be seen clearly that thick copper coating was successfully deposited on PEEK (Fig. 8d). In contrast, deposition on ABS in Fig. 8(b) shows only some particle embedding that was less than 1.0 MPa condition. This, together with the slightly negative DE value, indicates that erosion of the ABS substrate occurred. For PEI (not shown), particle embedding can be observed at $1.0 \mathrm{MPa}$, along with the development of waviness and valleys, indicating a higher degree of erosion than PEEK substrate under the same condition. This may account for the lower DE of copper on PEI compared to PEEK.

In general, considerable deposition of copper can be achieved on steel, PEEK and PEI substrates when cold spraying at $425{ }^{\circ} \mathrm{C}$ with the high-pressure Plasma Giken system.

\section{Discussion}

\section{Effect of Substrate}

The results of cold spray of various metal powders onto different substrates showed that different substrates rendered different responses during cold spray. For example, cold spray of copper at $425^{\circ} \mathrm{C}$ at $2.0 \mathrm{MPa}$ was successful on PEEK, PEI and steel substrates, but failed on ABS and CFRP. Therefore, the substrate can play a strong role in determining the cold sprayability of the metal powder.

It has been reported by researchers that cold spray of metals on the thermoplastic polymers is more successful than on the thermosetting polymers, due to the local softening mechanism in the thermoplastics (Ref 3,4). In this work, it was found that cold spray on the CFRP with a thermosetting matrix was unsuccessful at most conditions, and significant erosion of the substrate was observed at many conditions. For the thermoplastics, more positive results were obtained: on PEEK the tin coatings and thick copper coatings were achieved, on PEI the thick copper coatings were achieved, and on ABS the tin coatings were achieved.

The success with the thermoplastic substrates in this work, similar to those reported by other researchers (Ref $3,15)$, can be attributed to the local softening of the thermoplastics, namely when cold spraying at a temperature
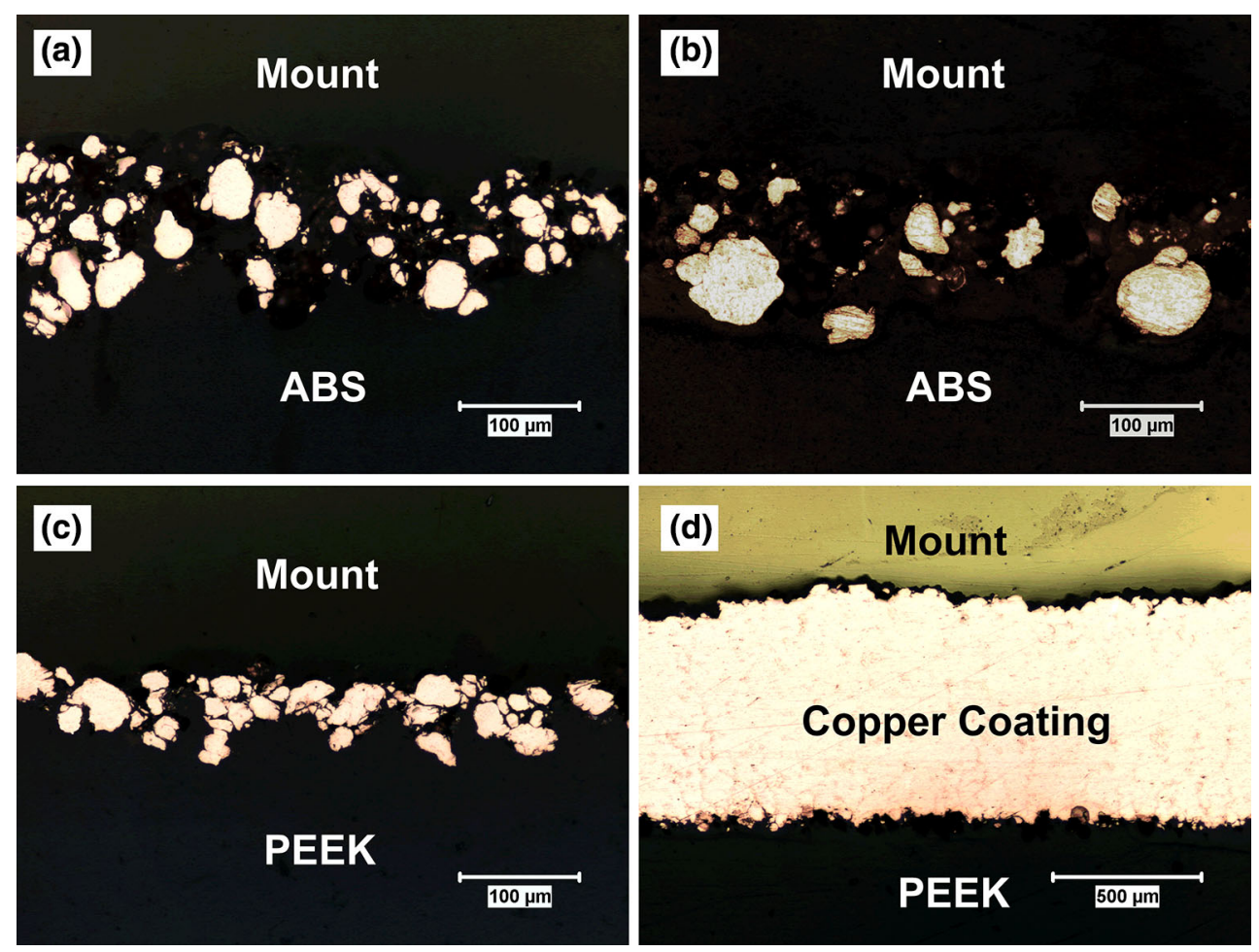

Fig. 8 Optical micrographs showing the cross sections of ABS (a, b) and PEEK (c, d) after cold spray of $\mathrm{Cu}$ at $425{ }^{\circ} \mathrm{C}$ at $1.0 \mathrm{MPa}(\mathrm{a}, \mathrm{c})$ and $2.0 \mathrm{MPa}(\mathrm{b}, \mathrm{d})$ 
close to or higher than the $T_{g}$ of the thermoplastic, the polymer surface that is exposed to the gas/particle stream softens; the metal particles penetrate the polymer and mechanically interlock with the polymer substrate upon cooling. With this mechanism, unlike the conventional splat formation, the metal particles do not experience significant plastic deformation while penetrating the thermoplastic surface (Ref 3). A typical characteristic of this mechanism is the waviness at the coating/substrate interface, which was observed frequently in this work.

At temperatures much lower than $T_{g}$, the polymers are in their glassy state and are relatively hard and brittle, so the particle embedding and mechanical interlocking are relatively difficult at low impact velocities since the local thermal softening is difficult (e.g., the failure in cold spray of tin at $200{ }^{\circ} \mathrm{C}$ on PEI with glass transition temperature of $215^{\circ} \mathrm{C}$ ), whereas significant erosion of the substrate may occur at high impact velocities due to the brittleness.

On the other hand, if the temperature is much higher than $T_{g}$, the mechanical properties of the thermoplastic may largely deteriorate, deposition on the thermoplastics is again difficult and erosion of the substrate may occur, due to the deterioration of polymer strength. An example for this is the cold spray of copper at $425{ }^{\circ} \mathrm{C}$ on ABS, whose $\mathrm{T}_{\mathrm{g}}$ is $105^{\circ} \mathrm{C}$. Fluid dynamics calculation by the KSS software (Ref 14) indicates that the copper particle temperature when reaching the substrate surface may exceed $200{ }^{\circ} \mathrm{C}$, which can lead to the significant deterioration of ABS strength and thus erosion. In contrast, the success with PEEK and PEI at $425{ }^{\circ} \mathrm{C}$ is due to their well-known capacity to retain their good mechanical properties at relatively high temperatures. The temperature dependence of the polymer properties is, therefore, important to cold spray of metals on polymer substrates.

Further investigation (e.g., single-particle impact test and numerical simulation) is needed to fully understand the particle-substrate interaction during impact, and thus the mechanism for cold spray particle and polymer substrate bond formation. In particular, it is important to determine the substrate temperature (and the particle/substrate interface temperature) during cold spray. The kinetics consideration (i.e., how fast the polymer softens and/or melts) may also add complications to this analysis.

\section{Development of the Cold Spray Window for Polymer Substrates}

Since the deposition of metal on polymers is also dependent on the substrate properties, the conventional deposition criteria (e.g., critical velocity and deposition window), which were developed on metallic substrate by assuming that the particle and substrate materials are identical (Ref 10 ), are not fully applicable if polymeric substrates are used. When a polymeric material is used in cold spray as the substrate, the result is either the deposition of the powder or erosion of the substrate, or the combination of both processes.

The feasibility of cold spraying a metal on a polymer is dependent on both the cold sprayability of the metal powder and the substrate properties. The substrate properties mainly decide whether the first layer can be formed or not. Generally, it should be relatively easy to deposit metal particles on the polymer materials with high erosion resistance, high ductility, high toughness and good plasticity (capable of being shaped or remolded). Further to this, soft particles (e.g., tin) may interlock with the polymer substrate better than the hard particles (e.g., iron), which may cause severe erosion of the substrate. It should be noted that the first layer is not necessarily a continuous layer, and could be a layer of embedded particles that do not bond with each other laterally.

To achieve a thick coating, further buildup on the first layer is required, and this is dependent on the cold sprayability of the metal powders as well as the bonding strength of the embedded particles with the polymer. The critical velocity of the metal powder must be reached so that the conventional adiabatic shear instability mechanism (Ref 16, 17) is enabled; meanwhile, the first layer cannot be eroded/removed. Therefore, it can be seen that depositing metal coatings onto polymer substrates is a complicated process and involves a number of influencing factors. Based on the deposition criteria proposed in previous paper (Ref 1), a method to determine the feasibility of cold spraying a metal on a polymer is present in Fig. 9.

There are several velocities in the schematic diagrams in Fig. 9: the velocity for the onset of particles mechanically interlocking with the substrate, $v_{\text {int }}$; the velocity at which the incoming particles erode the previously deposited particles/layer, $v_{\text {ero,pl }}$; the critical velocity for a specific metal powder, $v_{\text {crit }}$; and the velocity at which the DE of the powder drops back to zero (from the maximum) due to erosion, $v_{\text {ero }}$. There is also a significant erosion limit for CFRP (e.g., when erosion rate exceeds the potential deposition rate), as shown by the red dashed line in Fig. 9(b), which is also the upper bound of the erosion area in Fig. 9(d). To deposit a thick metal coating onto a polymer substrate, $v_{\text {crit }}$ and $v_{\text {eroppl }}$ delineate the lower and upper bounds, respectively. This means that the particle velocity must exceed the critical velocity of the metal powder, but cannot exceed the limit above which the first layer will be eroded. For example, when cold spraying copper onto PEEK or PEI, the deposition window is shown by the shaded area in Fig. 9(a). No coating but only some particle embedding would be obtained if sprayed at condition \#1, whereas a thick coating of copper can be achieved at condition \#2. If the particle velocity reaches the 
Fig. 9 Schematic diagrams showing the windows for developing the first layer and coating buildup when cold spraying metals onto polymer substrates
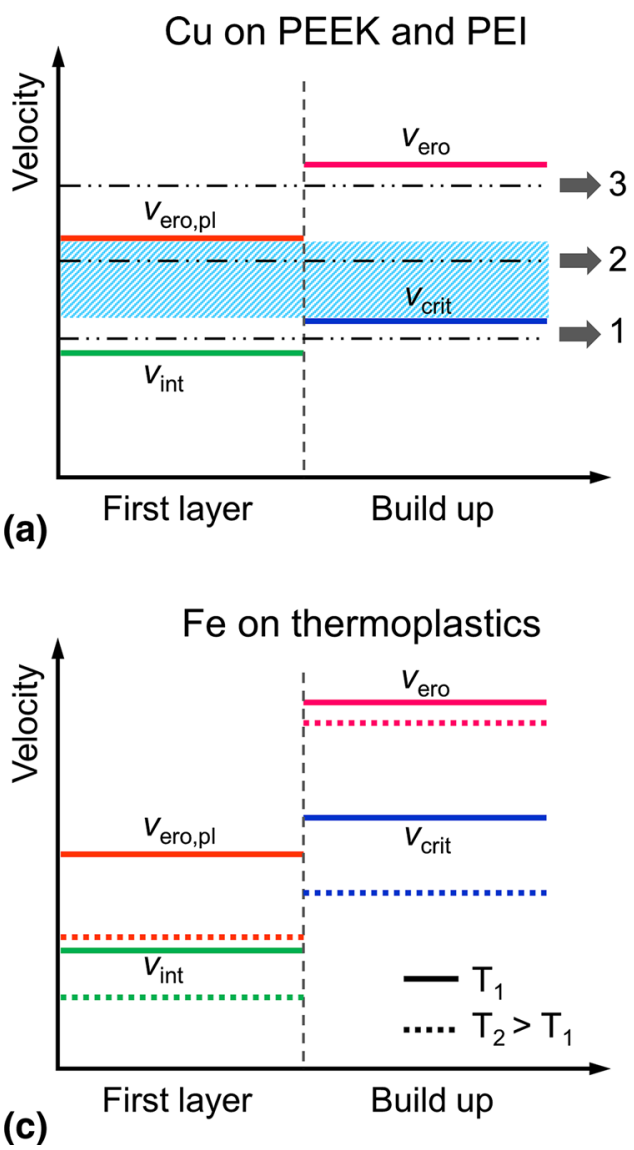
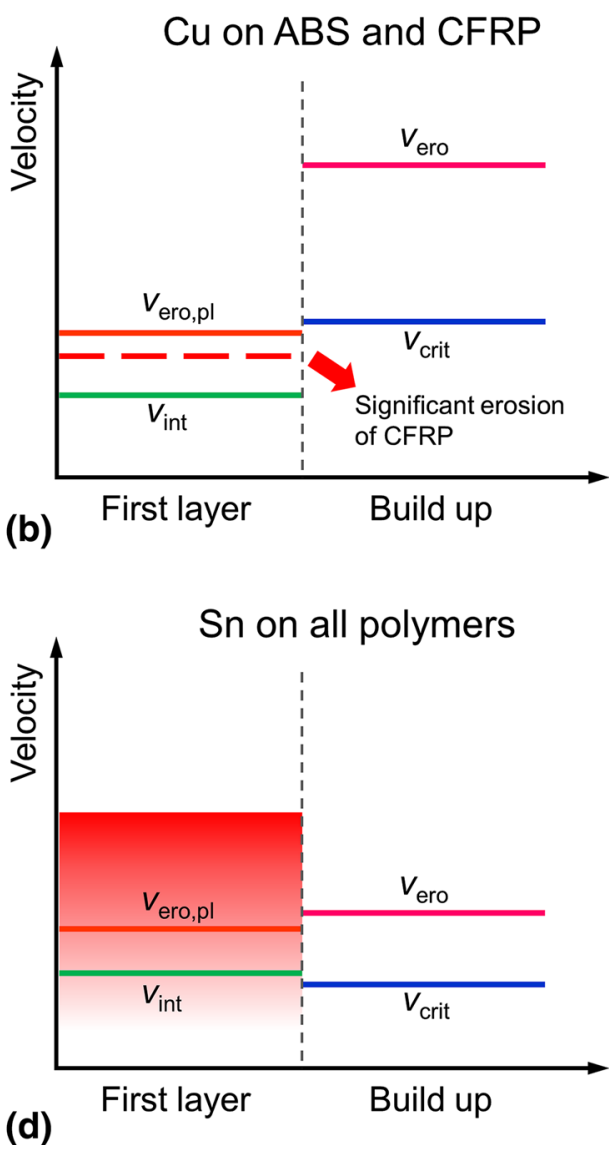

level of condition \#3, which was not assessed in this work, it is predicted that the thick copper coating can no longer be achieved or the coating-substrate bonding would be poor, due to the erosion of the first layer.

Unsuccessful cold spray of a metal powder on a polymer can be attributed to either the polymer end (first layer) or the metal powder end (buildup). The poor mechanical properties (e.g., erosion resistance) of the polymers and the low-strength bonding between the particles and the polymers are the main reasons from the polymer end. For example, cold spray of copper at $425^{\circ} \mathrm{C}$ on $\mathrm{ABS}$ and CFRP did not generate successful coatings in this work, and the schematic analysis is present in Fig. 9(b). For ABS, particle embedding can be formed successfully, but $v_{\text {ero,pl }}$ is too low since ABS lost its strength at the spray temperature, so there is no deposition window. For CFRP, no particles can be embedded and significant erosion of the substrate occurs at velocities below $v_{\text {crit }}$ of copper. On the other hand, metal powders that require high velocities or temperatures are not suitable for polymer substrates. An example is the iron powder in this work, for which a continuous coating cannot be successfully deposited onto PEEK or PEI at the conditions when thick copper coatings were obtained. As schematically shown in Fig. 9(c), $v_{\text {crit }}$ of iron is higher than $v_{\text {ero,pl }}$, so there is no deposition window.
When spraying at velocities above $v_{\text {crit }}$, the upcoming particles may erode/remove the previously embedded particles (first layer) in the thermoplastics surfaces, causing repetitive embedding-eroding process.

To summarize, the deposition window is that which falls within these "critical" velocities, with the highest DE due to the highest velocity of this window.

The window for the buildup is the conventional cold spray window of one metal powder, regardless of the metallic substrates. The values can be taken from the literature or calculated theoretically. For the first layer, the two velocities, $v_{\text {int }}$ and $v_{\text {ero,pl }}$, need to be determined experimentally. It may be dependent on the physical properties of the substrate (e.g., glass transition temperature, ductility and erosion resistance) and the physical properties of the metal powders (e.g., hardness and thermal conductivity), as well as the cold spray process parameters, such as gas temperature. As shown in Fig. 9(c), at a higher temperature, the deposition of the metal particles starts at a lower velocity, but the erosion of these deposited particles also becomes easier, so both $v_{\text {int }}$ and $v_{\text {ero,pl }}$ will decrease at higher gas temperature, but probably to different extents.

Erosion and deposition are always associated with each other and are difficult to distinguish. Erosion of the substrate may occur at a wide range of velocities, increasing 
with increasing velocity, as shown by the gradient area in Fig. 9(d). It is possible that the deposition window may overlap with the erosion window. The erosion of the polymer substrate is a transient process at the beginning of the deposition, as soon as a first layer is developed or the surface embedment is saturated, the erosion process is terminated. However, if $v_{\text {ero,pl }}$ is reached and the first layer is eroded, erosion of the substrate can be resumed. For CFRP or other thermosetting polymers, significant substrate erosion may occur at relatively low velocities and development of the first layer is difficult or even impossible for most metal powders.

\section{Conclusions}

Three metal powders, tin, copper and iron, were cold sprayed onto five different substrates, including three thermoplastics, PEEK, PEI and ABS, one polymeric composite with a thermosetting matrix, CFRP, and one metal, mild steel as the benchmark. The cold spray campaign was performed with both a low-pressure system and a high-pressure system to examine a wide range of particle velocities. In general, cold spray on the thermoplastic polymers rendered more positive results than the thermosetting polymers, due to the local thermal softening mechanism in the thermoplastics. Thick copper coatings were successfully deposited on PEEK and PEI at $425{ }^{\circ} \mathrm{C}$.

Cold spray onto polymeric substrates usually involves both the deposition of the metal powders and the erosion of the substrates, and the final deposition is a combined result of the two processes. To determine the cold spray window of a metal powder on a polymer substrate, the overall deposition is considered as a two-step process, the development of the first layer followed by the buildup. The overall spray window is the overlapping part of the windows for each process and is delineated by the critical velocity of the metal powder, $v_{\text {crit }}$, and the velocity limit above which the incoming particles will erode the previously deposited layer, $v_{\text {ero,pl }}$.

Acknowledgment The authors wish to acknowledge the financial support of the Consortium for Research and Innovation in Aerospace in Quebec and the Natural Sciences and Engineering Research Council of Canada. The industrial partners, Bombardier Aerospace, Bell Helicopter, $3 \mathrm{M}$ Canada, and the collaborating universities, École Polytechnique de Montréal and Université du Québec à Montréal are gratefully acknowledged. Mr. Frédéric Belval, Mr. JeanFrançois Alarie and Mr. Mario Lamontagne from National Research Council Canada, Boucherville, are acknowledged for their contribution to the cold spray experiments and velocity measurements.

\section{References}

1. H. Che, P. Vo, and S. Yue, Metallization of Carbon Fibre Reinforced Polymers by Cold Spray, Surf. Coat. Technol., 2017, 313, p 236-247

2. H. Che, X. Chu, P. Vo, and S. Yue, Cold Spray of Mixed Metal Powders on Carbon Fibre Reinforced Polymers, Surf. Coat. Technol., 2017, 329, p 232-243

3. A. Ganesan, M. Yamada, and M. Fukumoto, Cold Spray Coating Deposition Mechanism on the Thermoplastic and Thermosetting Polymer Substrates, J. Therm. Spray Tech., 2013, 22(8), p 12751282

4. M. Gardon, A. Latorre, M. Torrell, S. Dosta, J. Fernández, and J.M. Guilemany, Cold Gas Spray Titanium Coatings onto a Biocompatible Polymer, Mater. Lett., 2013, 106(3), p 97-99

5. D. Margerison and G.C. East, Chap. 1-Introduction, An Introduction to Polymer Chemistry, 1st ed., Pergamon, Oxford, 1967, p 1-39

6. M. Hough and R. Dolbey, The Plastics Compendium: Key Properties and Sources, Rapra Technology, Billingham, 1995

7. M.F. Ashby and K. Johnson, Materials and Design: The Art and Science of Material Selection in Product Design, 1st ed., Butterworth-Heinemann, Oxford, 2002

8. D. Rosato, D.P. Di Mattia, and D.V. Rosato, Designing with Plastics and Composites: A Handbook, Springer, US, 1991

9. F. Gärtner, T. Schmidt, T. Stoltenhoff, and H. Kreye, Recent Developments and Potential Applications of Cold Spraying, $A d v$. Eng. Mater., 2006, 8(7), p 611-618

10. T. Schmidt, F. Gärtner, H. Assadi, and H. Kreye, Development of a Generalized Parameter Window for Cold Spray Deposition, Acta Mater., 2006, 54(3), p 729-742

11. E. Irissou, J.-G. Legoux, B. Arsenault, and C. Moreau, Investigation of Al-Al2O3 Cold Spray Coating Formation and Properties, J. Therm. Spray Tech., 2007, 16(5-6), p 661-668

12. R.C. Dykhuizen and M.F. Smith, Gas Dynamic Principles of Cold Spray, J. Therm. Spray Tech., 1998, 7(2), p 205-212

13. T. Schmidt, H. Assadi, F. Gärtner, H. Richter, T. Stoltenhoff, H. Kreye, and T. Klassen, From Particle Acceleration to Impact and Bonding in Cold Spraying, J. Therm. Spray Tech., 2009, 18(5-6), p 794-808

14. T. Stoltenhoff, H. Kreye, and H.J. Richter, An analysis of the Cold Spray Process and its Coatings, J. Therm. Spray Tech., 2002, 11(4), p 542-550

15. X.L. Zhou, A.F. Chen, J.C. Liu, X.K. Wu, and J.S. Zhang, Preparation of Metallic Coatings on Polymer Matrix Composites by Cold Spray, Surf. Coat. Technol., 2011, 206(1), p 132-136

16. H. Assadi, F. Gärtner, T. Stoltenhoff, and H. Kreye, Bonding Mechanism in Cold Gas Spraying, Acta Mater., 2003, 51(15), p 4379-4394

17. M. Grujicic, C.L. Zhao, W.S. DeRosset, and D. Helfritch, Adiabatic Shear Instability Based Mechanism for Particles/Substrate Bonding in the Cold-Gas Dynamic-Spray Process, Mater. Design, 2004, 25(8), p 681-688

18. M. Biron, Chap 4.-Detailed Accounts of Thermoplastic Resins, Thermoplastics and Thermoplastic Composites, 2nd ed., William Andrew Publishing, Norwich, 2013, p 189-714 